\title{
Abilities in the blind spot of testing regimes: Eliciting the benefits and the limitations of participatory research approaches for numeracy in adult basic education
}

\author{
Wiebke Curdt ${ }^{1}$ (D) . Silke Schreiber-Barsch ${ }^{1,2}$
}

Published online: 5 August 2020

(c) The Author(s) 2020

\begin{abstract}
In the past decade, the numeracy component in adult basic education has gained scholarly attention. The issue has been addressed by large-scale assessments of adults' skills and intergovernmental policy agendas, but also by qualitative research into numeracy from the perspective of social practice theory. However, some aspects of numeracy are still under-researched. This article argues that adults with learning difficulties (also referred to by some as intellectual disabilities) and their numeracyrelated abilities are still hidden in the blind spot of large-scale testing regimes. To address this underrepresentation, the authors present an overview of the key paradigms of a global testing culture, outline their two areas of interest, disability and numeracy, and identify the blind spots of large-scale international surveys. They consider ways of extending the range of methodological approaches to investigating (literacy and) numeracy, and opt for a participatory research approach, for which they identify five guiding principles. They showcase and reflect on these guiding principles by presenting selected data from a small-scale qualitative study on numeracy practices of adults with learning difficulties. Their aim is to demonstrate the benefits and limitations of using participatory research approaches in the context of investigating numeracy among all members of a country's adult population.
\end{abstract}

Keywords numeracy as social practice - participatory research approaches · disability $\cdot$ learning difficulties $\cdot$ qualitative research

Wiebke Curdt

wiebke.curdt@uni-hamburg.de

Silke Schreiber-Barsch

Silke.Schreiber-Barsch@uni-hamburg.de

1 Adult and Further Education, University of Hamburg, Hamburg, Germany

2 Centre for Higher and Adult Education, Stellenbosch University, Stellenbosch, South Africa 


\section{Résumé}

Les aptitudes dans l'angle mort des procédures de tests : révéler les avantages et les limites des méthodes de recherche participative concernant la numératie dans l'éducation de base des adultes - Durant la décennie passée, la numératie, en tant qu'élément de l'éducation de base des adultes, a suscité l'attention des scientifiques. Des évaluations à vaste échelle des compétences des adultes et des programmes politiques intergouvernementaux se sont consacrés à cette question qui a également fait l'objet de recherches qualitatives du point de vue de la théorie de la pratique. Cependant, certains aspects de la numératie restent sous-documentés. Le présent article affirme que les adultes qui ont des difficultés d'apprentissage (que certaines personnes appellent aussi des déficiences intellectuelles) et leurs aptitudes en matière de numératie restent invisibles, demeurant encore dans l'angle mort des procédures de tests menées à vaste échelle. Pour se pencher sur cette sous-représentation, les auteures livrent une vue d'ensemble des paradigmes clés de la culture mondiale du test, exposent brièvement leurs deux champs d'intérêt, le handicap et la numératie, et font un relevé des angles morts des grandes enquêtes internationales. Elles envisagent des façons d'élargir l'éventail des approches méthodologique pour explorer (la littératie et) la numératie, et optent pour une approche par la recherche participative pour laquelle elles déterminent cinq principes directeurs. Elles les mettent en avant et réfléchissent à leur sujet en présentant des données sélectionnées, extraites d'une petite étude qualitative sur les pratiques de numératie d'adultes ayant des difficultés d'apprentissage. Elles se proposent ainsi de démontrer les avantages et les limites des méthodes de recherche participative dans le contexte de l'étude de la numératie chez tous les membres de la population adulte d'un pays.

\section{Introduction}

Measuring individual learning outcomes and comparing them among individuals and nation states by means of worldwide league tables have become predominant strategies for monitoring and assessing the efficiency of education and training systems. Thus, numbers and testing are being used as policy tools (Lingard 2011; Sellar 2015; Smith 2017; Lingard et al. 2017). This rise of test-based "infrastructures of accountability" (Anagnostopoulos et al. 2013), which extend pure data collection and management to "complex assemblages of technology, people and policies" (ibid., p. 13), also applies to academia and the policy sector in terms of their approach to dealing with the issues of adult literacy and numeracy (Hamilton et al. 2015; Evans 2019). Over the past decades, large-scale skills assessments, such as the Programme for International Student Assessment (PISA) or the Programme for the International Assessment of Adult Competencies (PIAAC), have substantially contributed to increased knowledge and data production on a global level, administered 
by transnational organisations such as the Organisation for Economic Co-operation and Development (OECD 2019). ${ }^{1}$

Framing adult basic education as a global education policy concern has also been supported by the establishment of worldwide educational goals by intergovernmental organisations. One of the most prominent endeavours is the United Nations 2030 Agenda with its seventeen Sustainable Development Goals (SDGs) (UN 2015). The fourth of these goals, SDG 4, aims to

ensure inclusive and equitable quality education and promote lifelong learning opportunities for all (ibid., p. 14).

Among the ten targets of this education-focused goal, SDG target 4.6 calls on United Nations (UN) Member States to ensure that "all youth and a substantial proportion of adults, both men and women, achieve literacy and numeracy" by 2030 (ibid., p. 17).

Over time, all these measurement and monitoring endeavours of academia and the policy sector have helped to substantiate the relevance of adult numeracy, derived from its

recognized role in contributing to the empowerment, effective functioning, economic status, and well-being of citizens and their communities (Gal 2000, p. ix).

However, some studies are also drawing attention to the impact and the consequences of a development towards extensive testing regimes. For example, Leon Tikly has argued that indicators and quantitative monitoring exercises have evolved in academia and the policy sector into a sort of "gold standard" (Tikly 2015, p. 239), taking the nature of testing and its standards for granted.

In this article, we pursue Tikly's (2015) line of argument, and use William Smith's (2017) analysis of a global testing culture as our conceptual framework. Our aim is to explain why we consider certain adult abilities to be overlooked in international (literacy and) numeracy surveys because they remain off the radar of testing regimes. Two aspects guide our elaboration. First, we discuss the concepts of abilities and skills used in testing regimes such as PIAAC for measuring individual skills and classifying them based on standardised scores. In our view, these concepts follow a rather deficit-oriented logic, ${ }^{2}$ and we suggest using a resource-oriented perspective ${ }^{3}$ which is particularly relevant in the context of disability.

\footnotetext{
1 Both PISA and PIAAC are OECD surveys. For more information about PISA, see https://www.oecd. org/pisa/. For more information about PIAAC, see https://www.oecd.org/skills/piaac/ [both accessed 3 July 2020].

2 In the context of disability with respect to learning, the deficit-oriented logic argues that an individual is lacking something, e.g. cognitive and/or behavioural skills necessary for achieving predetermined learning goals, a lack which is to be "corrected" by medical or other treatments.

3 The notion of a resource-oriented perspective (discussed in more detail later in this article) refers to both the subject's own resources (harnessing an individual's extant cognitive and/or behavioural skills, i.e. the multiple resources at their disposal for achieving learning progress) and the environment's resources at the subject's disposal.
} 
The second aspect concerns the blind spots of large-scale international performance surveys which occur due to the scope of these surveys' methodological approach and are thus inherent in their findings on adult numeracy. We agree with some scholars' concerns (Jackson et al. 2018, p. 248; Evans 2019, p. 68) that largescale standardised definitions and tests in numeracy may not satisfactorily draw a comprehensive picture of adults' diversity and the broad range of their everyday numerate social practices. Having identified the blind spots of large-scale surveys, we then complement the detection of their presence with the insights and added value which can be drawn from the use of small-scale qualitative approaches and principles of participatory research. ${ }^{4}$

The structure of this article is as follows: We begin with an overview of the key paradigms of a global testing culture. Next, we outline our two areas of interest, disability and numeracy, identifying the blind spots of large-scale international surveys, and we consider ways of extending the range of methodological approaches to investigating (literacy and) numeracy. We present the theoretical and conceptual frameworks which serve as our basis for discussing testing regimes in the field of adult numeracy and disability. Next, we debate the benefits and the limitations of using principles of participatory research in small-scale qualitative studies. After identifying five guiding principles, we showcase and reflect on them by presenting selected data from our current research ${ }^{5}$ on numeracy practices of adults with learning difficulties ${ }^{6}$ (also referred to by some as intellectual disabilities). We conclude our article by summing up the benefits and the limitations of using such principles in the context of investigating numeracy among all members of a country's adult population.

\section{Key paradigms of a global testing culture}

The discourse in the field of education and lifelong learning about the epistemological foundations, methodological approaches and the scope of findings of largescale surveys has been enriched by Smith (2017). According to his analysis of the

\footnotetext{
${ }^{4}$ In a nutshell, participatory research strives to do research with people, not on people. To this end, methodologies and methods are used which, to varying degrees, actively engage participants of a study as agents and thus encourage forming alliances and dividing power among researchers, practitioners and participants. The concept is discussed in more detail later in the article.

5 Our current research, which investigates "Numeracy practices of adults with learning difficulties" (NumPuD), is part of the Hamburg Numeracy Project, funded by Landesforschungsförderung Hamburg (2017-2020).

6 The term learning difficulties describes attitudes, norms and personal perceptions of abilities also described by others as intellectual disabilities (the reasons why we do not use the latter terminology here are discussed in more detail later in this article). Both terminologies represent a particular understanding of and conceptual approach to disability. However, what is considered "an intellectual disability" varies worldwide. According to the World Health Organization (WHO), "Intellectual disability means a significantly reduced ability to understand new or complex information and to learn and apply new skills (impaired intelligence). This results in a reduced ability to cope independently (impaired social functioning), and begins before adulthood, with a lasting effect on development” (WHO n.d.).
} 
emergence of a global testing culture in the light of world culture theory (Ramirez $2003),{ }^{7}$ the global testing culture is driven by two key paradigms - positivism and individualism $^{8}$ - thus favouring an environment where high-stakes standardised "testing becomes synonymous with accountability, which becomes synonymous with education quality" (Smith 2017, p. 7).

Pursuant to these paradigms, Smith distinguished among five core values of such a culture (ibid., pp. 12-13). These are: (1) education as a human right, leading to mandatory worldwide policies to ensure education equity; (2) prioritisation of academic intelligence, privileging cognitive and scientific dimensions; (3) faith in science and its findings as the "objective arbiter of truth"; (4) decentralisation of education systems; and (5) neoliberalism as a political-economic concept that fuels most of society and uses accountability measures for assessing education systems' efficiency. Smith further argued that these values set the legitimate behavioural standards for all parties involved and their respective social roles, which stipulate that individual "behaviour that fails to align with the cultural model provided is considered deviant and formally or informally sanctioned" (ibid., p. 14).

In our view, these key paradigms and core values point to factors which are most relevant factors for the analysis we present in this article, which aligns with other scholarly work in social sciences. In his work on scientific history, Nikolas Rose elaborated on how societal systems became dependent on evolving their citizens' human capital and thus "sought to codify, calculate, supervise, and maximize the level of functioning of individuals" (Rose 1988, p. 197). This helped constitute a "system of individualization in terms of measurement and diagnosis rather than status and worth" (ibid., p. 197). More recently, Camilla Addey has brought forward the same line of argument, explaining why low adult skills levels of literacy (also applicable to numeracy) are considered threatening to society's "threshold of functionality" (Addey 2018, p. 326). In this sense, testing regimes have served as the backbone of a "global literacy", having become the predominant and "single story of literacy" (ibid., p. 324).

The necessity of debating these conceptual frameworks and drivers for policy and research becomes particularly evident when taking into account adults with learning difficulties and their numeracy-related abilities, which we have chosen as our particular areas of interest in this article.

\footnotetext{
7 World culture theory seeks to explain similarities and a convergence of structure and policy in educational systems and their global actors worldwide, regarding global rationalisation in education as driven by leitmotifs such as science, progress or accountability.

${ }^{8}$ In a nutshell, positivism is a philosophical ideology which "assumes that reality can be observed and objectively measured" (Smith 2017, p. 12), e.g. by quantitative statistical techniques. Individualism refers to the "belief that when individuals are given freedom to choose, they will act in their own selfinterest" (ibid., p. 12). Against the backdrop of a global testing culture, people are then understood as being "fully aware of and able to comprehend the information necessary to successfully maneuver within their particular environment" (ibid., p. 12).
} 


\section{Disability and numeracy-related abilities}

\section{Disability}

Taking a closer look at disability (our first area of interest in this article) in the context of large-scale international surveys reveals that the respective terminologies and conceptualisations of impairment and disability differ substantially worldwide and are far from clear-cut (WHO 2007, pp. 17-24; Neuhäuser and Steinhausen 2013, pp. 16-21; Schreiber-Barsch et al. 2020, p. 583). To distinguish among the respective approaches, three conceptual models are commonly used: (1) medical/individualistic; (2) social; and (3) cultural/relational models of disability (Barnes 2014).

Medical models interpret disability as a primarily individual and biological factor of deviation to be "fixed" by medical or other treatments. The standard definition of the World Health Organization in its International Classification of Functioning, Disability and Health (WHO 2001) seeks to broaden the strict medical and social understanding by recognising the category's complexity, and captures disability as arising from a dynamic interaction between a person's health condition (individual impairment) and the contextual factors of activities and participation.

Likewise taking social participation into account, the UN Convention on the Rights of Persons with Disabilities states:

Persons with disabilities include those who have long-term physical, mental, intellectual or sensory impairments which in interaction with various barriers may hinder their full and effective participation in society on an equal basis with others (UN 2006, p. 3).

In this article, we follow the cultural model, which again broadens the analytical view and strongly scrutinises the legitimacy of widely unquestioned normative standards and classifications. It emphasises the intersections across biological, social, cultural and psychological aspects, as well as attitudes, norms and personal perceptions; it also pays attention to power structures. This model is advocated in the field of disability studies (e.g. Waldschmidt 2017; Goodley 2017), ${ }^{9}$ where disability is considered

neither as only an individual fate, as in the individualistic-reductionist model of disability, nor as merely an effect of discrimination and exclusion, as in the social model (Waldschmidt 2017, p. 24).

Instead, the cultural model recognises "impairment, disability and normality as effects generated by academic knowledge, mass media, and everyday discourses" (ibid., p. 24).

This understanding is also informed by the theoretical approach of ableism (Campbell 2009). Like Smith (2017) and Addey (2018), Fiona Kumari Campbell

\footnotetext{
9 Disability studies emerged as an academic discipline in the 1980s. One important feature is the use of interdisciplinary and intersectional approaches to explore issues of disability and impairment in their interdependence with social, political, cultural, economic and power-driven factors.
} 
criticised the one-sided and often invisible social architecture of an ability regime, where skills and competencies are believed to determine a person's degree of functionality. She defined ableism as

a network of beliefs, processes and practices that produces a particular kind of self and body (the corporeal standard) that is projected as the perfect, speciestypical and therefore essential and fully human (Campbell 2009, p. 5).

Disability in this deficit-oriented view is thus "cast as a diminished state of being human" (ibid., p. 5). In contrast to this deficit-oriented view and in accordance with the cultural model, our own ambition was to choose and use a term which would reflect a resource-oriented perspective on disability. The outcome of our quest for such a term is that we decided to adopt the term learning difficulties instead of intellectual disabilities, as suggested by self-advocacy groups such as People First (Stalker 2014; Walmsley and Johnson 2016; Di Lorito et al. 2018, p. 669). However, we also recognise that this term does not simply erase social stigma or the need for reflecting on its inherent norms and attributions.

\section{Numeracy}

Over the past decade, numeracy, our second area of interest in this article, has received increased scholarly attention. It has also been incorporated in large-scale assessments, establishing the benefit of providing a standard definition and comparable data. PIAAC defines numeracy as

the ability to access, use, interpret, and communicate mathematical information and ideas, in order to engage in and manage the mathematical demands of a range of situations in adult life (Gal et al. 2009, p. 21).

This definition was extended by Vince Geiger, Merrilyn Goose and Helen Forgasz to a rich interpretation of numeracy, which they circumscribed as

the knowledge and capabilities required to accommodate the mathematical demands of private and public life, and to participate in society as informed, reflective, and contributing citizens (Geiger et al. 2015, p. 531).

This takes into account both the mastery of school mathematics and

the capability to: make sense of non-mathematical contexts through a mathematical lens; exercise critical judgement; and explore and bring to resolution real world problems (ibid., p. 531).

It is this rich interpretation of numeracy which guides the rationale of our article and the research methodology we used in our study.

Despite this growing attention, the extant body of scholarship on adult numeracy and disability, particularly on the subcomponent of learning difficulties, is still very limited (see for example Prendergast et al. 2017; Lane et al. 2019). This dearth echoes data collection omissions in large-scale assessment surveys. While the PIAAC background questionnaire (BQ) used in the United States (US) collected 
data on disability status, it did not gather any information on intellectual disability (Patterson and Paulson 2015, p. 11). The 2012 German PIAAC survey (GESIS 2012) left out persons living in institutional settings (e.g., prisons and homes for the elderly or for adults with disabilities), which massively reduced the probability that adults with learning difficulties would be included in the sample (see SchreiberBarsch et al. 2020, p. 582). Furthermore, stocktaking papers on the respective epistemological foundations of survey designs have documented the predominance of cognitive testing and behaviourism rationales that favour medical models of disability, and thereby deficit-oriented perspectives (Magne 2003; Tan et al. 2019). Taking into account Smith's key paradigms of a global testing culture outlined above thus strengthens our appraisal that individualism and positivism also seem to have a strong impact on adult numeracy and disability research.

Yet, across these theoretical and conceptual approaches, what becomes evident is the key relevance accorded to the concept of human abilities when measuring skills and debating numeracy and literacy. Researchers largely agree that in contrast to understandings of skills and competencies (Rychen and Salganik 2003, p. 43), abilities constitute a basic blend of a human individual's mostly innate reservoir of physical and mental aptitudes (Straka and Macke 2009, p. 15). This reservoir provides a substantial yet extendable foundation - extendable because abilities mirror an individual combination of knowledge and of cognitive, corporal and motivationalemotional dispositions to do what one intends to do (or not do). The gradually more future-oriented meaning of still unrealised potential is often called capability. The concept of skills differs from that of abilities and capabilities by also drawing on learned or acquired routinised abilities and proficiencies with reference to performing a particular task (ibid., p. 15).

The dilemma that arises from the disability-specific component of a deficit-oriented perspective of human abilities ties in with commonly used standards imposed on disability, particularly learning difficulties. As declared by Robert Edgerton as early as the 1960s, from the standpoint of sociological stigma theory, ${ }^{10}$

no other stigma is as basic as mental retardation in the sense that a person so labeled is thought to be so completely lacking in basic competence (Edgerton 1967, p. 207).

Assuming that these labelling mechanisms are still at work today reinforces our view that the development towards global testing regimes with their paradigms of positivism and individualism fuels this deficit-orientation. Methodologies which involve classifications of skills that assess individual deviations from society's "threshold of functionality" (Addey 2018, p. 326) tend to exclude parts of the population and/or prioritise survey designs which preclude data collection on abilities beyond the given standards, as outlined above.

\footnotetext{
10 Sociological stigma theory seeks to explain stigma as a social marker that indicates a deviance from dominant social norms. A social stigma can be an attribute, a behaviour, or a reputation which is socially discrediting for a person or a social group.
} 
Arguing from the perspective of disability studies, Jan Weisser therefore called disability a phenomenon that triggers an "ability conflict" (Weisser 2018, p. 99). The conflict arises out of a suspected or proven "clash" between a person's (perceived) abilities and an environment's context-contingent expectations of certain degrees of functioning that are considered basic in that environment. The conflict culminates in the case of disability within the context of an ability regime (see also Tan et al. 2019). Such conflicts cannot be ultimately erased, they are a regular part of learning processes and might also (unintentionally) occur within the context of participatory research, as exemplified below in the section where we discuss selected data from our small-scale qualitative study on numeracy practices of adults with learning difficulties. However, it is imperative to identify and question normative frames, powerdriven mechanisms and deficient impacts on learning.

Factoring in the key paradigms and core values of a global testing culture (Smith 2017) as components which are also fuelling the scholarly debate on adult numeracy and disability stresses the need for extending methodological approaches in order to diminish blind spots of testing regimes and promote a resource-oriented perspective on human abilities. In this sense, we understand all adults as having an innate ability to engage (more or less) in numeracy-related learning activities.

\section{Extending the range of methodological approaches}

To extend the range of methodological approaches which seem suitable for assessing adult numeracy, we use Jeff Evans, Keiko Yasukawa, David Mallows and Brian Creese's (2017) distinction between top-down and bottom-up analyses. Top-down (generalising) analyses follow the positivist and individualist key paradigms and "seek to explain numeracy at a global level" (Evans et al. 2017, p. 18; emphasis in original). By contrast, bottom-up approaches operate in a "grounded" way. They aim to explore "the sets of practices that a particular group or community of adults may engage in" (ibid., p. 19), thus taking such practices as starting points for their analyses, rather than the items and scores used to measure predefined and standardised skills.

In our view, this understanding of practices has the potential to diminish blind spots of testing regimes and should be distinguished from a quantitative, generalising concept of practices as a real-context "numerate behaviour", which is measured, for example, in terms of its frequency (OECD 2019, p. 24). By contrast, we align our theoretical approach with the rich tradition of scholarly works on literacy and numeracy based on social practice theory ${ }^{11}$ (Lave 1988; Street et al. 2008; Yasukawa, Rogers et al. 2018). Andreas Reckwitz (2003), for example, emphasised that a practice is not just a behaviour, but rather incorporates a more or less visible

\footnotetext{
11 Social practice theory seeks to understand and explain human action and interaction within societal structures, rather than isolating the subject (individuals or social groups) and the object (structures and systems) from each other. Social practice theory assumes that "it is in practice that individuals shape and are shaped by systems" (Yasukawa, Jackson et al. 2018, p. 6; emphasis in original). This explains its close relationship to the philosophy of pragmatism (see the footnote 12).
} 
pattern of how particular things "get done", which involves a person's body (enactment of the practice), tacit and explicit forms of embodied knowledge, capabilities and meanings and material resources (artefacts). In this way, social practice theories "seek to overcome a subject/object dualism" (Yasukawa, Jackson et al. 2018, p. 6).

Social practice theorist Reckwitz (2003) and also disability studies scholar Anne Waldschmidt (2017) both base their conceptual approaches on cultural studies research and refer to the philosophy of pragmatism ${ }^{12}$ (Joas 1992) in order to respond to that dualism and to strengthen the subject's viewpoint in its social, historical, cultural and power-related embeddedness.

Research on adult numeracy through this lens thus

focuses on what people do with numeracy through social interactions in particular contexts, rather than on people's performance of mathematical skills in isolation of context (Yasukawa, Jackson et al. 2018, p. 13; emphasis in original).

In this sense, knowledge on numeracy practices allows researchers

to explore the conceptualizations, the discourse, the values and beliefs and the social relations that surround numeracy events as well as the context in which they are located (Street et al. 2008, p. 20).

This context-contingent and subject-oriented perspective on human action and interaction within societal structures (of power) and socially shared meaning is coherent with the theoretical assumptions of research in disability studies, as they seek "to investigate the relations between symbolic (knowledge) systems, categorization and institutionalisation processes, material artefacts, practices and 'ways of doing things"” (Waldschmidt 2017, p. 24).

Based on this line of argument and with regard to research methodologies, the suitability of approaches such as a grounded theory methodology (GTM), ${ }^{13}$ particularly in its interpretation by Anselm Strauss and Juliet Corbin (1990), is widely supported (Strübing 2014). We highlight the fruitful encounter of social practice theories, disability studies and GTM in the following sections by discussing the application of participatory research in exploring the numeracy-related abilities of adults with learning difficulties.

\footnotetext{
12 The philosophy of pragmatism is a theoretical strand that is strongly influenced, for example, by the works of US-American philosopher John Dewey with regard to questions of democracy and education. From a methodological standpoint, pragmatism supports the relevance of human experiences and explores practices as a manifestation of the subject's interpretations of his/her reality, interests and needs. 13 Grounded theory methodology is a methodology in the social sciences that has developed different strands of interpretation. In general, it uses an iterative process (an inductive comparative method of data analysis) in data sampling, analysis and theory development. This is in contrast to the hypothetico-deductive model which is, for example, applied by quantitative statistical techniques.
} 


\section{Participatory research: identifying its guiding principles}

Participatory research is associated with a range of theoretical strands, such as critical theory or pragmatism (Wright et al. 2010, p. 222). ${ }^{14}$ However, these overlap to form a common ground in participatory research, based on its rejection of a strict positivist view on social science research and on its emphasis on the subject and the subjective in research ${ }^{15}$ - embedded in societal structures (of power) (see also Schreiber-Barsch and Rule, forthcoming). In participatory research, participation is perceived as not only the aim but also the key process of undertaking research (Bergold and Thomas 2012). In our view, participatory research methodologically enables research designs that correspond with the multi-perspective analysis demanded by the cultural model of disability (see above, Waldschmidt 2017).

This approach fundamentally alters the understanding of the epistemological relationship among science, research and human action (Wright et al. 2010, p. 227; Strübing 2014, p. 38; Waldschmidt 2017). According to Hella von Unger's seminal work on the topic, "participatory research" is a generic term for approaches that aim to explore, reconstruct and ultimately influence social reality by conducting research in a participatory way (von Unger 2014, p. 1). Implementing this kind of research in the context of disability has noticeably increased over the last few decades (see for example Chappell 2000; Rule and Modipa 2012; Townsend 2013; Stalker 2014).

As for research on learning difficulties, this is not yet widespread (Stalker 2014; Di Lorito et al. 2018; Hollomotz 2018, p. 154) and moreover still tends to prioritise research on, not with, people (Buchner and Koenig 2008, p. 32). Its conceptual strands vary according to the role assigned to persons with disabilities (Chappell 2000; Walmsley and Johnson 2016). In this article, and in the research approach we adopted in our study, we focus on those strands that conduct participatory research in the form of a partnership between researchers and persons with disabilities, a socalled alliance (Chappell 2000).

Across scholarly works which emerged from the fields of social and educational sciences, social work and psychology, we have identified five guiding principles of participatory research approaches (see Table 1). This list provides the heuristic framework for debating our research on numeracy and for presenting selected data from our small-scale qualitative study on numeracy practices of adults with learning difficulties in the following sections. Moreover, these five principles once again demonstrate the distinction of participatory research from the key paradigms and core values of a global testing culture (in particular its values (2) and (3)).

\footnotetext{
${ }^{14}$ In a nutshell, critical theory has been established as a school of thought that stresses the reflective assessment and critique of society and culture and their inherent power structures. It does this by challenging ideological viewpoints that assume universal truths, pure rationality or individual autonomy from any context or environment. (For pragmatism, see footnote 12.)

15 In participatory research, the subject is seen to be the individual human embedded in his/her social, political, historical and personal context; thus, not de-contextualised as in an individualist approach. The subjective stresses the relevance of the subject's viewpoint on her/himself as part of these contextual factors.
} 


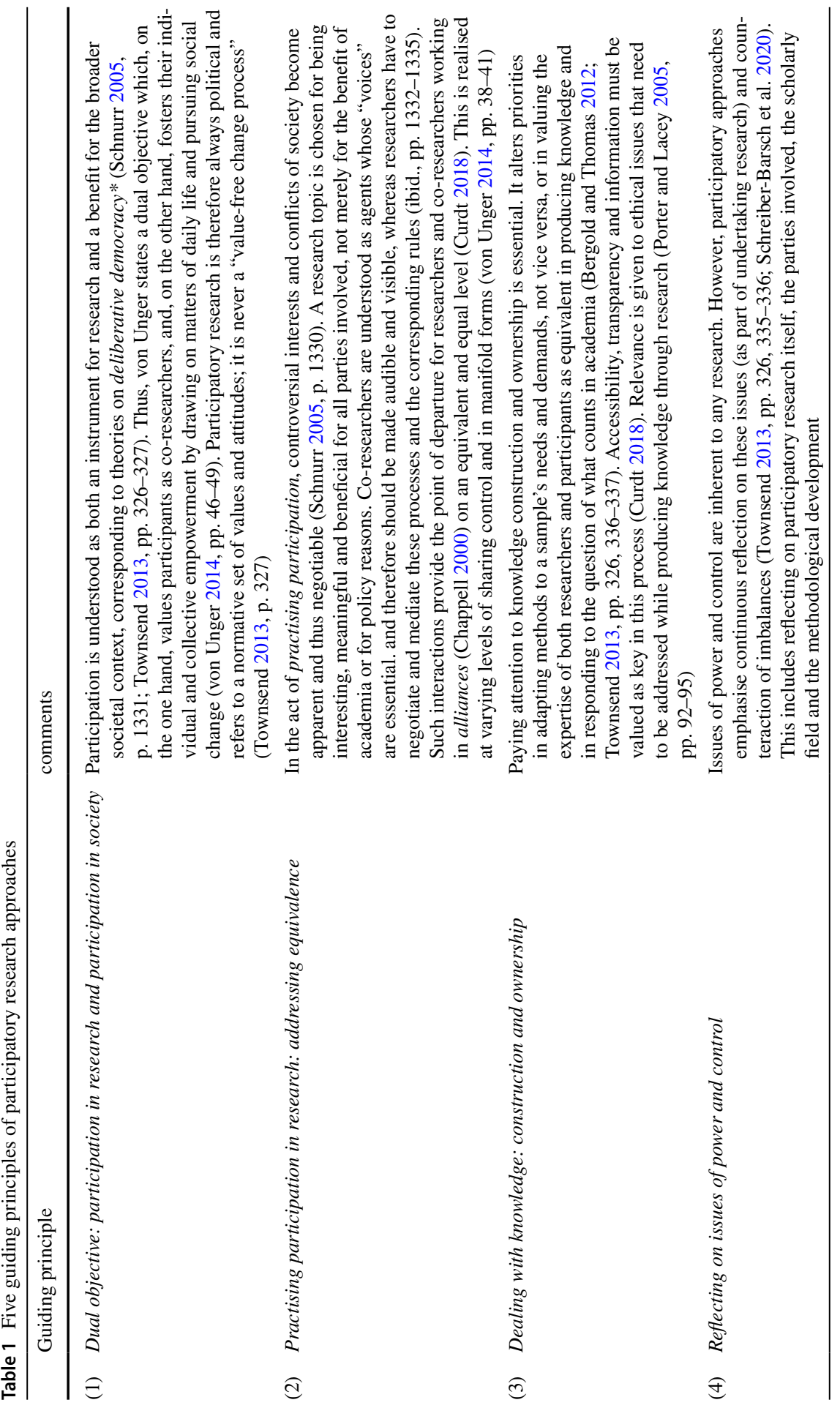




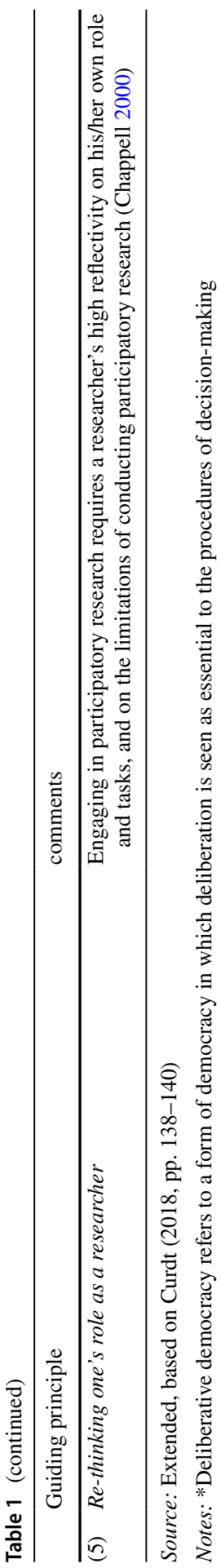


We will revisit these guiding principles as we explore the selected data from a small-scale qualitative study we conducted on numeracy practices of adults with learning difficulties. Below, we present a methodological outline of our study. It is followed by our reflections on our own experiences in applying participatory research with adults with learning difficulties, for which the five guiding principles form a useful presentational structure.

\section{Conducting participatory research: exploring numeracy practices of adults with learning difficulties}

To demonstrate the benefits and the limitations of participatory research approaches, we use our current research on numeracy practices of adults with learning difficulties as an empirical example. In this article, we focus on methodological considerations (for a detailed literature review and discussion focused on adult numeracy, see Schreiber-Barsch et al. 2020). We begin with a brief introductory overview of our research design, which frames our discussion of selected data from our small-scale qualitative study.

The limited extant knowledge on numeracy practices of adults with learning difficulties made us opt for an exploratory study (Creswell 2003, pp. 198-199). ${ }^{16}$ Our study was guided by three interrelated questions:

(1) In which ways do adults with learning difficulties engage in numeracy practices in their everyday contexts?

(2) To what extent are numeracy-related abilities mirrored in these practices?

(3) In particular, what are the meanings they ascribe to their practices?

\section{Methodology}

To answer the above set of questions, we designed an in-situ study (Yasukawa, Jackson et al. 2018, p. 14), following a bottom-up approach in adult basic education research (Evans et al. 2017, p. 18). Such small-scale qualitative studies do not intend to make generalisations, but seek an in-depth understanding of subjective sensemaking processes as they unfold in everyday contexts. The setting of our research was the city of Hamburg in Northern Germany, and the study was conducted in German. Our unit of analysis ${ }^{17}$ was social practices (not behavioural or cognitive facets of individuals), which shifted the attention from assessing the (deficient) skills of individuals "towards a consideration of how things get done and how social practices are shaped” (Williams et al. 2018, p. 170).

\footnotetext{
16 As its name suggests, the intention of an exploratory study is to explore a problem or research question in order to gain a better understanding and a clearer definition of this problem or question rather than setting out to find a conclusive answer based on hard factual evidence.

17 A unit of analysis is the main object of interest in an investigation/a research study.
} 
To carry out this research endeavour in the context of disability with a particular interest in learning difficulties, we decided to intersect the methodological principles of participatory research and qualitative research (Buchner and Koenig 2008, p. 16; O'Brien et al. 2014; von Unger 2014, p. 5) - the latter in the form of grounded theory methodology (GTM) (Strauss and Corbin 1990; Strübing 2014). It recognises adults with learning difficulties as experts in their ways of acting out numeracy.

For the iterative GTM process of data sampling, analysis and theory development (called theoretical sampling), we followed three sensitising concepts (Kelle and Kluge 2010, pp. 28-30): ${ }^{18}$ First, we took on board the rich interpretation of numeracy compiled by Geiger et al. (2015), outlined above in the subsection on numeracy. Second, we reviewed the extant knowledge on what to identify as facets of numeracy (for details, see Schreiber-Barsch et al. 2020, pp. 585-586). We synthesised numeracy facets constituting the analytical reference framework for our selected context of adults with learning difficulties: space and shape; numbers and calculating; size and measurement; patterns and structures; probabilities, frequencies and chances; and artifacts (ibid., p. 586). Third, in exploring ways of acting out numeracy in everyday life, we applied the following widely used classification of the four arenas of adult everyday life (ibid., p. 584): (1) work, (2) education and training, (3) living conditions (including financial and material resources; type of living [residential care, assisted, with parents, on their own, with partners]; taking care of basic needs [e.g., shopping for food], etc.) and (4) free time (e.g., pursuing a personal life and interests; health and well-being; taking part in society and community).

Against this backdrop, the GTM process led us to develop a multilevel participatory research design consisting of three steps based on different methods of data collection, including a between-method triangulation. The steps were (1) shadowing adults with learning difficulties in their ways of acting out numeracy, as insitu observations $(n=11)$; (2) interviewing adults with learning difficulties on their numeracy practices $(n=13)$; and (3) conducting focus group discussions with professionals working with adults with learning difficulties in the listed arenas of everyday life $(n=3)$. In accordance with the principles of participatory research, we set up a parallel group of co-researchers (adults with learning difficulties) as a main pillar of the alliance (Chappell 2000) between researchers and adults with learning difficulties (the co-researchers were not participants in the shadowing or the interviews).

The sampling for the three levels of the research design, as well as for the group of co-researchers, was in accordance with the GTM process of theoretical sampling that did not pursue a statistical representation (generalisation), but a conceptual or analytical representation (Strübing 2014, p. 31; Merriam and Tisdell 2016, p. 33). ${ }^{19}$

\footnotetext{
18 Sensitising concepts are theoretical lenses that the researcher uses as prior theoretical knowledge as possible lines of inquiry for looking at the phenomenon under investigation and the evolving data. They are thus to be differentiated from standard definitions or operationalisations used by hypothetico-deductive models, determined before the study's beginning.

19 Whereas a statistical representation seeks to ensure the highest possible representation of a study's sampling and, thus, of its findings, a conceptual or analytical representation aims to ensure the representation of the data collected and the sensitising concepts used for developing a substantive theory for the phenomenon being investigated.
} 
In this case, it was a representation of a set of social practices as the unit of analysis, not of individuals according to (among others) their cognitive facets, such as scores on a scale measuring their intelligence quotient (IQ). Accordingly, we ensured a balanced distribution of participants across contexts and genders, and we aimed for maximal contrast in living conditions and ages (Schreiber-Barsch et al. 2020, p. 586).

To conduct shadowing and interviews, it was necessary for the participants to have abilities at their command that allowed them to communicate verbally with us, move without personal assistance and be able and willing to give us insights into their ways of acting out numeracy. This profile corresponded to persons who would be described as experiencing mild-to-moderate difficulties in the WHO "activities and participation" component in terms of capacity and performance qualifiers (WHO 2001, pp. 237-239). This led us to use snowball sampling and to seek participants via channels (such as particular journals) or places that were frequently and commonly used by members of the target group. Finally, we addressed potential ethical issues by placing emphasis on obtaining informed consent for our procedures of data collection, analysis and dissemination (Porter and Lacey 2005, pp. 92-95; Buchner 2008).

By using the principles of participatory research, we were thus able to gather data from persons who are underrepresented in the extant scholarly literature and difficult to reach using traditional test methods. This was reflected in the common worry amongst our participants that this would "be a maths test". Throughout the data collection processes, the participants were able to ask questions about the methods and were also aware that, if they requested this, they could stop participating in the study $(n=0)$.

\section{Co-researchers}

We organised the so-called participatory research group (PRG) with 9 co-researchers (adults with learning difficulties). Our first concern was to provide the PRG with information and learning opportunities to become familiar with the university and the nature of research. Moreover, we provided information about our research, preliminary findings and challenges, and put our way of conducting research up for debate. This meant involving the co-researchers in the steps of planning and implementing the shadowing and the interviews. In this process, we discussed, for example, the intelligibility of the interview questions and asked for advice. This led one co-researcher to suggest a question that we then successfully placed as the opening question in the interviews in order to collect rich descriptions of acting out numeracy in daily life: "Please tell us about your daily life: what does your normal day look like?"

This PRG subsequently led to a more formalised setting as part of the study programme at the Faculty of Education, University of Hamburg (the participatory research workshop [PRW 1]). In this setting, students and adults with learning difficulties collaboratively work together on small self-organised research projects. While we thought of continuing with the focus on the numeracy topic, the 
co-researchers expressed their interest in a broader range of issues. Consequently, we continued to provide information on the ongoing research and put methodological questions and preliminary findings up for debate, complemented by organised multiplier events to which we also invited the participants of the shadowing and interview sessions. However, the participants of the PRG/PRW chose their own research areas of interest, also in the subsequent series (PRW II and III) (for details, see Gundlach et al. 2019).

\section{Shadowing, interviews and focus groups}

We used the shadowing method (Bøe et al. 2017) for our in-situ explorations of numeracy practices (lasting between 2 and 7.5 hours). The 11 participants' ages ranged from 18 to 80 years ( 6 males, 4 females and 1 transgender), 6 were living with their parents, 3 were living in supportive housing or assisted living facilities, and 2 were living alone. Regarding their personal circumstances, 2 received an (invalidity) pension, 4 were employed in a sheltered job or workshop, 4 attended vocational schools, and 1 was completing an internship. We asked the participants to allow us to shadow them while they performed their daily activities as they usually did; thus, they were in full control of the circumstances of the shadowing (McDonald and Simpson 2014). We agreed on a meeting point, and from that point, a researcher followed the participants wherever they went. The researcher used a recording template ${ }^{20}$ (observational record sheet) throughout the shadowing.

However, as Marit Bøe et al. (2017, p. 608) aptly remarked, researching social practices requires a complementary method to capture their complexity. After completing the shadowing, we therefore conducted semi-structured interviews $(n=13)$ (lasting from 30 minutes to 2.5 hours each). Due to our use of snowball sampling and to individual preferences, there was only a small overlap $(n=3)$ between the shadowing participants and the interview sample. The adults who were interviewed were aged 18-42 ( 7 male, 6 female). Four of them lived with parents, 5 alone (one together with a spouse, one with a daughter) and 4 in supportive housing or assisted living facilities. The majority ( 7 people) were employed at a sheltered job or workplace, 3 at a school and 3 were completing an internship. For our interview method, we combined principles from problem-oriented interviews (Witzel 2000) ${ }^{21}$ and from guidelines for conducting qualitative interviews with adults with learning difficulties (Buchner 2008). ${ }^{22}$ We offered flexibility in terms of where and when the interview

\footnotetext{
20 The items of the template were based on our synthesis of numeracy facets (see the subsection on methodology above). The template included a vertical column (listing place, situation, event) and a horizontal line (listing space/orientation, time, order [sorting, comparing], numbers and digits, quantity, social interaction/ contacts, artifacts [objects] and comments).

21 A problem-oriented interview is a data collection method employed in qualitative-oriented research. It seeks to elicit the experiences, perceptions and reflections of the respondents with regard to a particular issue (i.e. the problem).

22 Tobias Buchner (2008) identified a set of guiding principles for implementing qualitative interviews with adults with learning difficulties, tackling the sampling, the choice of the research setting and issues of communication during the interview situation (see also Porter and Lacey 2005).
} 
would be conducted, used plain language (Buchner 2008, p. 522; Hollomotz 2018, p. 153), a clear structure and questions that were assumed to be relevant to the participant's experiences (tested by the co-researchers). To this end, we also used seven picture cards with motives in the broadest sense of numeracy which we presented during one interview sequence to initiate further reflection on everyday numeracy.

In the iterative process of data analysis, the data collected in the shadowing and the interviews demonstrated that professionals working in the listed arenas of daily life play a pivotal role for acquiring, using and developing numeracy-related abilities. This insight led to the third step of our research design. We conducted three focus group interviews (Mangold 1960; Barbour 2007), each lasting approximately 45-60 minutes and involving a total of 15 professionals (working in a vocational school for the group under scrutiny, in supportive housing or assisted living facilities, and in support structures for sheltered workplaces). The aim was to gather collective experiences and opinions on numeracy practices of adults with learning difficulties, particularly on ways of professionally supporting numeracy learning and development in everyday life contexts.

In this article, due to our focus on participatory research with adults with learning difficulties, we limit the following glance at selected data from the study described in the previous section to those parts of the data collection that were conducted with these adults.

\section{A glance at selected data from our small-scale qualitative study}

To illustrate and reflect on the benefits and the limitations of participatory research approaches, in this section we provide insights into selected data collected during the shadowing and the interviews (the participants' names have been anonymised; a CAPITALISED word signifies the participant's emphasis). ${ }^{23}$ We present these selected data using the five guiding principles of participatory research (see Table 1).

\section{(1) Dual objective: participation in research and participation in society}

We endeavoured to realise this dual objective in several methodological ways. These included the research design with the part of the co-researchers who were recognised in their expertise in giving advice for planning, implementing and analysing the different stages of data collection. This role also included participating physically as a member of a research group in the usually highly exclusive venue of a university. Likewise, the multiplier events with debates on preliminary findings and feedback about the methods used in the data collection opened a space for a dialogical exchange on numeracy, on the relationship between researchers and participants and on fostering abilities through research as a way of empowerment. Several participants reported that by being part of

${ }^{23}$ We translated the excerpts from the recorded dialogues into English for the purposes of this article. 
the research, they had started to reflect on their ways of acting out numeracy and realised abilities that they had never identified as having something to do with "mathematics".

This dialogical process of capacity building and empowerment also became apparent in the process of the data collection itself due to the participatory methodology we had opted for. During the shadowing, several times, the participants asked about what the researcher wrote in the observational protocol and what phrases such as "social interactions" meant (see footnote 20 describing our recording template), which started a dialogue with the researcher. In an interview sequence, a participant had explained how he made sure to arrive punctually at a specific place, and the interviewer had asked for an example of how he had learned that (e.g., using a street map). The participant was puzzled, then laughed:

Participant: "That is difficult to answer. One just learns it. Or not? [laughing] I do not know."

Researcher: "Yes."

Participant: "How have YOU learnt it, [name of the researcher]?"

(I_1_\#176-178\#)

\section{(2) Practising participation in research: addressing equivalence}

The participatory research approach clearly made voices visible and audible which remain largely unheard and underrepresented in the extant scholarly body of knowledge. Considering these numeracy-related abilities in their own right thus contributed not only to striking a better balance by complementing/extending the existing spectrum of research findings, but also to identifying controversial interests and societal conflicts. This became apparent when, on the one hand, our participants showed evidence of their successful numeracy proficiencies and strategies and then, on the other hand, devalued their abilities by closing their narratives with remarks such as "but I am only a learner of a special needs school" (I_10_\#360\#), or "Well, I was always only told by other people ... but I would say, from the level, wait, how do you say that? 5th grade or so at the most" (I_8_\#524\#).

The limitations of realising this principle in our case became evident due to the funding structure of the research, which meant a given time schedule and an $a$ priori set research question. In these parts of the research process, that is, choosing the research topic and planning the overall design as a collaborative outcome of the alliance, participation had to be kept very limited. Nonetheless, throughout our research, we paid particular attention to several ways and forms of realising participation, considering adapted methods, information, consultation, involvement and co-determination (Schnurr 2005, p. 1336; von Unger 2014, pp. 39-52). We therefore designed the data collection process from the perspective and subjective viewpoints of adults with learning difficulties, recognising their expertise and prioritising it as the key reference. 


\section{(3) Dealing with knowledge: construction and ownership}

For the third principle, the development of a multilevel participatory research design played a pivotal role. To produce a rich database, it was necessary to obtain observation data (shadowing) and descriptions (interviews) of numeracy practices - through methods that would recognise the participants as experts and be suitable to their life situations. In general, this principle demands the researcher's awareness of subtle mechanisms of knowledge construction processes. The reason for this is that if these mechanisms are not reflected and based only on the researcher's knowledge and expectations, they might, as demonstrated in the next scene, unintentionally give rise to an ability conflict (Weisser 2018) between a person's (perceived) abilities and an environment's context-contingent expectations of certain degrees of functioning that are considered basic in that environment.

As explained above, we used picture cards in the interviews, with the intention of initiating further reflection on issues of numeracy in matters of daily life. However, our analysis showed that in several cases, this disrupted the participants' flow of conversation. For example, one participant was clearly puzzled when shown a picture card of a woman holding a note with numbers written on it:

Participant: "Yes. I have no clue about this, about this note."

Researcher: "About this note, you mean this one here, right?"

Participant: "Yes." [pause]

Researcher: "But maybe ... So that is, what could that be?"

Participant: "Calculating?"

Researcher: "Calculating?"

Participant: "Mathematics? [pause] Learning difficulty? I do not know." [...]

[Looking at another picture card that visualises a street traffic situation with road signs.]

Participant: "I have... well, about this road sign, I have no idea because I do not drive a car."

Researcher: "Okay."

Participant: "And I come ..., or I just do not know what this means."

$$
\text { (I_10_\#326-332\#; \#392-394\#) }
$$

Thus, the abilities that this participant articulated or perceived with regard to specific tasks and situations ("understanding" a pattern of numbers on a note; driving a car) clashed with the researcher's expectations of what could be matters of daily life and relevance. Thus, in this case, this particular method had its limitations, because it failed to link to relevant matters of the participant's daily life and unintentionally produced the feeling of being in a test situation, which obviously influenced the production of knowledge. The principles of participatory research, however, helped to discover and reflect on this limitation. 


\section{(4) Reflecting on issues of power and control}

Whereas in the interviews, the control of the procedures (choreography of questions and answers) relied more strongly on the researcher conducting the interview, the participants controlled the consent for the interview as such - the place and the time and the extent and the content of their narratives. In the shadowing, the possibility of exercising control became even more obvious. One researcher met with a participant near a train station after she had finished her vocational training course; the only information given was that we would follow her in spending free time and doing her shopping. The following event occurred when changing trains (noted in the recording template):

Participant: "Do we want to go to the [shopping centre]?"

Researcher: "You decide. I'm just following you today."

Participant: "Then we'll go to the [shopping centre]."

She goes purposively to the platform. We stand at the station and wait.

Participant: "We can also go to the airport. I was there the other day with my friend."

Researcher: "Yes, we can do that, too."

Participant: "Or to the [shopping centre]."

Two minutes before the train arrives, the participant changes her mind.

Participant: "We'll take my route to school. Going home, that's not that far.

That's better."

She turns and goes back downstairs to change platforms.

Participant: "The train is already there!"

She quickly runs up the stairs and jumps into the train.

I [the researcher] run after her.

(Sh_3_para 7_1-7)

On the one hand, this sequence illuminates that shadowing allows gaining a firsthand view of numeracy practices (routines) and numeracy-related abilities incorporated in everyday contexts. The participant demonstrated her familiarity with the train station (spatial orientation); she knew the destinations of certain trains and could adapt to the variety of routes and spontaneously change her mind and desired destination (patterns and routines; understanding numbers). Doing this, she planned ahead and decided on the basis of comparing how long the journey would take on different routes (handling the unit of time). On the other hand, the researcher was required to take a back seat, follow the participant and interpret the data being offered. By contrast, the participant gained control of the research situation, made decisions and changed her mind.

\section{(5) Rethinking one's role as a researcher}

Continuously reflecting on the research process is inherent in the bodies of knowledge consulted, the methods' benefits and limitations and/or the different interests of 
the parties involved (including academia, the policy sector, researchers, participants and the funding agency). The aim is to expose and to debate these contested terrains, exemplified by, for example, unintentionally giving rise to an ability conflict due to the chosen method (picture cards). Likewise, using shadowing as a method requires well-balanced and careful data collection. Sharing the participant's daily life for hours and engaging (cautiously) in conversations (Bøe et al. 2017, p. 609) could give them the impression of having made a new friend, which would then need to be corrected by the researchers as being only part of their professional role and task. In general, intersecting principles of participatory research and GTM require the researcher to maintain a higher degree of openness with regard to prior planning, designing and conducting the research than would be necessary in the use of standardised and quantitative methodologies. This is illuminated, for example, by the decision-making processes of the co-researcher group or by sharing control while shadowing and conducting interviews.

\section{Conclusion}

Against the backdrop of key paradigms and core values of a global testing culture (Smith 2017), we argued in this article that using a rich interpretation of numeracy and a cultural model of disability in intersection with methodological principles of participatory research, GTM and bottom-up approaches in literacy and numeracy research has the potential of diminishing blind spots of testing regimes. It not only enables the inclusion of persons and their social practices in the literacy and numeracy spectrum that are not yet part of the extant scholarly knowledge, but also strengthens a resource-oriented perspective on human abilities. In this way, the theoretical encounter among social practices theories, disability studies and GTM is further nuanced and substantiated for scholarly debate. Moreover, we predict that the heuristic framework we have presented of the guiding principles of participatory research, with its illustrated benefits and limitations, will also be usable for research beyond the context of disability, thereby fostering research not on, but with hard-toreach and marginalised learners and social groups.

Within this field of enquiry, our evidence has shown that the shadowing method is suitable for research in the context of social practices and learning difficulties, thus broadening the methodological debate in education sciences. Applying this method proved to be particularly pertinent in the case of very limited extant knowledge (on numeracy practices of this group) and of participants who might show cognitive limitations in verbally explaining their points of view (though this subsequently proved to be the case only to a very small extent in some of the interviews). However, deploying methods such as shadowing and interviews still requires certain abilities and might, therefore, not be suitable in cases of e.g. more complex impairments.

To sum up (and as emphasised elsewhere; Schreiber-Barsch and Rule, forthcoming), our aim is to contribute evidence towards the epistemological, methodological, ethical and political importance of a participatory ethos in research, not only - but in particular - with regard to persons with disabilities such as adults with learning 
difficulties. This ethos strives for learners' capacity building and empowerment through research as opposed to the use of learners merely for the benefit of academic research or the policy sector. The ultimate goal of research in this participatory approach is, thus, the collective transformation of social reality.

Acknowledgements Open Access funding provided by Projekt DEAL. As part of the Hamburg Numeracy Project, our research on "Numeracy practices of adults with learning difficulties" (Numerale Praktiken und Dis/ability; NumPuD), is funded by Landesforschungsförderung Hamburg (2017-2020) (LFF-FV 52).

Open Access This article is licensed under a Creative Commons Attribution 4.0 International License, which permits use, sharing, adaptation, distribution and reproduction in any medium or format, as long as you give appropriate credit to the original author(s) and the source, provide a link to the Creative Commons licence, and indicate if changes were made. The images or other third party material in this article are included in the article's Creative Commons licence, unless indicated otherwise in a credit line to the material. If material is not included in the article's Creative Commons licence and your intended use is not permitted by statutory regulation or exceeds the permitted use, you will need to obtain permission directly from the copyright holder. To view a copy of this licence, visit http://creativecommons.org/licen ses/by/4.0/.

\section{References}

Addey, C. (2018). Assembling literacy as global: The danger of a single story. In M. Milana, J. Holford, S. Webb, P. Jarvis, \& R. Waller (Eds.), The Palgrave international handbook of adult and lifelong education and learning (pp. 315-335). London: Palgrave Macmillan.

Anagnostopoulos, D., Rutledge, S. A., \& Jacobsen, R. (Eds.). (2013). The infrastructure of accountability: Data use and the transformation of American education. Cambridge, MA: Harvard Education Press.

Barbour, R. (2007). Doing focus groups. Los Angeles, CA: SAGE.

Barnes, C. (2014). Understanding the social model of disability: Past, present and future. In N. Watson, A. Roulstone, \& C. Thomas (Eds.), Routledge handbook of disability studies (pp. 12-29). New York: Routledge.

Bergold, J., \& Thomas, S. (2012). Partizipative Forschungsmethoden: Ein methodischer Ansatz in Bewegung [Participatory research methods: A methodological approach in motion]. Forum: Qualitative Sozialforschung/Forum: Qualitative Social Research, 13(1), Art. 30. Retrieved 28 November 2019 from http://nbn-resolving.de/urn:nbn:de:0114-fqs1201302.

Bøe, M., Hognestad, K., \& Waniganayake, M. (2017). Qualitative shadowing as a research methodology for exploring early childhood leadership in practice. Educational Management Administration \& Leadership, 45(4), 605-620. https://doi.org/10.1177/1741143216636116.

Buchner, T. (2008). Das qualitative Interview mit Menschen mit so genannter geistiger Behinderung: Ethische, methodologische und praktische Aspekte [Qualitative interviews with people with socalled intellectual disabilities: Ethical, methodological and practical aspects]. In G. Biewer, M. Luciak, \& M. Schwinge (Eds), Begegnung und Differenz: Menschen - Länder - Kulturen. [Encounter and difference: People - countries - cultures] (pp. 516-528). Beiträge zur Heil- und Sonderpädagogik. Bad Heilbrunn: Klinkhardt.

Buchner, T., \& Koenig, O. (2008). Methoden und eingenommene Blickwinkel in der sonder- und heilpädagogischen Forschung von 1996-2006: Eine Zeitschriftenanalyse [Methods and perspectives adopted in special and curative education research from 1996-2006: A journal analysis]. Heilpädagogische Forschung, XXXIV(1), 15-34.

Campbell, F. K. (2009). Contours of ableism: The production of disability and ableness. New York: Palgrave Macmillan.

Chappell, A.L. (2000). Emergence of participatory methodology in learning difficulty research: understanding the context. British Institute of Learning Disabilities. British Journal of Learning Disabilities, 28(1), 38-43. https://doi.org/10.1046/j.1468-3156.2000.00004.x. 
Creswell, J. W. (2003). Research design: Qualitative, quantitative, and mixed methods approaches (2nd ed.). Thousand Oaks, CA: SAGE.

Curdt, W. (2018). Heterogenität in integrativen Sportgruppen am Beispiel Special Olympics Unified Sports ${ }^{\circledR}$. Eine rekonstruktive Analyse im Kontext partizipativer Forschung [Heterogeneity in integrative sports groups using the example of Special Olympics Unified Sports $₫$ : A reconstructive analysis in context of participatory research]. Leipzig: Leipzig University. Retrieved 29 June 2020 from https://ul.qucosa.de/landing-page/?tx_dlf[id]=https $\% 3 \mathrm{~A} \% 2 \mathrm{~F} \% 2 \mathrm{Ful} . q u c o s a . d e \% 2 \mathrm{Fapi} \% 2 \mathrm{Fquco}$ sa\%253A21056\%2Fmets.

Di Lorito, C., Bosco, A., Birt, L., \& Hassiotis, A. (2018). Co-research with adults with intellectual disability: A systematic review. Journal of Applied Research in Intellectual Disabilities, 31(5), 669686. https://doi.org/10.1111/jar.12435.

Edgerton, R. B. (1967). The cloak of competence: Stigma in the lives of the mentally retarded. Berkeley, CA: University of California Press.

Evans, J. (2019). Adult skills surveys and transnational organisations: Globalising educational policy. In J. Evans, S. Ruane, \& H. Southall (Eds.), Data in society: Challenging statistics in an age of globalisation (pp. 65-77). Bristol: Policy Press.

Evans, J., Yasukawa, K., Mallows, D., \& Creese, B. (2017). Numeracy skills and the numerate environment: Affordances, opportunities, supports and demands. Adults Learning Mathematics, 12(1), $17-26$.

Gal, I. (2000). The numeracy challenge. In I. Gal (Ed.), Adult numeracy development: Theory, research, practice (pp. 9-31). Cresskill, NJ: Hampton Press.

Gal, I., Alatorre, S., Close, S., Evans, J., Johansen, L., Maguire, T., Manly, M. \& Tout, D. (2009). PIAAC numeracy: A conceptual framework. OECD Education Working Paper No. 35. Paris: OECD (PIAAC Numeracy Expert Group). https://doi.org/10.1787/220337421165.

Geiger, V., Goose, M., \& Forgasz, H. (2015). A rich interpretation of numeracy for the 21st century: A survey of the state of the field. ZDM-The International Journal on Mathematics Education, 47(4), 531-548. https://doi.org/10.1007/s11858-015-0708-1.

GESIS (Gesellschaft Sozialwissenschaftlicher Infrastruktureinrichtungen) (2012). PIAAC Deutschland 2012 - Hintergrundfragebogen [PIAAC Germany 2012: Background Questionnaire]. Mannheim: GESIS Leibnitz-Institut für Sozialwissenschaften. Retrieved 29 November 2019 from https://www. gesis.org/fileadmin/piaac/Downloadbereich/PIAAC_BQ_Final_deutsch.pdf.

Goodley, D. (2017). Disability studies: An interdisciplinary introduction (2nd ed.). Los Angeles, CA: SAGE.

Gundlach, H., Panzer, M., Rückforth, B., \& Schreiber-Barsch, S. (2019). Lebenslanges Lernen ${ }^{\text {inklusiv }}{ }^{\text {: Ein- }}$ blicke in das Lehrprojekt „Partizipative Forschungswerkstatt“ an der Universität Hamburg [Inclusive lifelong learning: Insights into the "Participative research workshopW teaching project at the University of Hamburg]. Erwachsenenbildung und Behinderung, 2, 49-61.

Hamilton, M. E., Maddox, B., \& Addey, C. (2015). Literacy as numbers: Researching the politics and practices of international literary assessment. Cambridge: Cambridge University Press.

Hollomotz, A. (2018). Successful interviews with people with intellectual disability. Qualitative Research, 18(2), 153-170. https://doi.org/10.1177/1468794117713810.

Jackson, K., Rogers, A., \& Yasukawa, K. (2018). Expanding and deepening the terrain: Numeracy as social practice. In K. Yasukawa, A. Rogers, K. Jackson, \& B. V. Street (Eds.), Numeracy as social practice: Global and local perspectives (pp. 243-254). London/New York: Routledge.

Joas, H. (1992). Von der Philosophie des Pragmatismus zu einer soziologischen Forschungstradition [From the philosophy of pragmatism to a sociological research tradition]. In H. Joas (Ed.), Pragmatismus und Gesellschaftstheorie [Pragmatism and social theory] (pp. 23-65). Frankfurt a. M.: Suhrkamp.

Kelle, U., \& Kluge, S. (2010). Vom Einzelfall zum Typus [From individual case to type] (2nd ed.). Wiesbaden: VS Verlag.

Lane, C., van Herwegen, J., \& Freeth, M. (2019). Exploring the approximate number system in Sotos syndrome: Insights from a dot comparison task. Journal of Intellectual Disability Research, 63(8), 917-925. https://doi.org/10.1111/jir.12604.

Lave, J. (1988). Cognition in practice. Mind, mathematics and culture in everyday life. Cambridge: Cambridge University Press.

Lingard, B. (2011). Policy as numbers: Ac/counting for educational research. The Australian Educational Researcher, 38(4), 355-382. https://doi.org/10.1007/s13384-011-0041-9. 
Lingard, B., Martino, W., \& Rezai-Rashti, G. (2017). Testing regimes, accountabilities and education policy: Commensurate global and national developments. In B. Lingard, W. Martino, \& G. RezaiRashti (Eds.), Testing regimes, accountabilities and education policy (pp. 1-18). London and New York: Routledge.

Magne, O. (2003). Literature on special educational needs in mathematics: A bibliography with some comments (4th edn). Educational and Psychological Interactions, 124. Malmö, Sweden: School of Education. Retrieved 4 December 2019 from http://citeseerx.ist.psu.edu/viewd oc/download?doi=1 0.1.1.463.5013\&rep=rep1\&type=pdf.

Mangold, W. (1960). Gegenstand und Methode des Gruppendiskussionsverfahrens. Frankfurt a.M.: Europäische Verlagsanstalt.

McDonald, S., \& Simpson, B. (2014). Shadowing research in organizations: The methodological debates. Qualitative Research in Organizations and Management: An International Journal, 9(1), 3-20. https://doi.org/10.1108/QROM-02-2014-1204.

Merriam, S. B., \& Tisdell, E. J. (2016). Qualitative research: A guide to design and implementation (4th ed.). San Francisco, CA: Jossey-Bass.

Neuhäuser, G., \& Steinhausen, H.-C. (2013). Epidemiologie, Risikofaktoren und Prävention [Epidemiology, risk factors and prevention]. In G. Neuhäuser, H.-C. Steinhausen, F. Hässler, \& K. Sarimski (Eds.), Geistige Behinderung: Grundlagen, Erscheinungsformen und klinische Probleme, Behandlung, Rehabilitation und rechtliche Aspekte [Intellectual disabilities: Basic principles, manifestations and clinical problems, treatment, rehabilitation and legal aspects] (pp. 15-29). Stuttgart: Kohlhammer.

O’Brien, P., McConkey, R., \& García-Iriarte, E. (2014). Co-researching with people who have intellectual Disabilities: Insights from a National Survey. Journal of Applied Research in Intellectual Disabilities, 27, 65-75. https://doi.org/10.1111/jar.12074.

OECD (Organisation for Economic Cooperation and Development). (2019). The Survey of Adult Skills: Reader's companion (3rd edn). Paris: OECD Publishing. https://doi.org/10.1787/f7023 8c7-en.

Patterson, M.B., \& Paulson U.G. (2015). Adult transitions to learning in the USA: What do PIAAC survey results tell us? Commissioned paper. Washington, DC: American Institutes for Research. Retrieved 17 January 2019 from https://static1.squarespace.com/static/51bb74b8e4b0139570dd f020/t/54da7639e4b0990535ec333a/1423603257773/Patterson_Paulson_PIAAC.pdf.

Porter, J., \& Lacey, P. (2005). Researching learning difficulties: A guide for practitioners. London: Paul Chapman Publishing.

Prendergast, M., Spassiani, N. A., \& Roche, J. (2017). Developing a mathematics module for students with intellectual disability in higher education. International Journal of Higher Education, 6(3), 169-177. https://doi.org/10.5430/ijhe.v6n3p169.

Ramirez, F. (2003). The global model and national legacies. In K. Anderson-Levitt (Ed.), Local meanings, global schooling: Anthropology and world culture theory (pp. 239-254). New York: Palgrave Macmillan.

Reckwitz, A. (2003). Grundelemente einer Theorie sozialer Praktiken: Eine sozialtheoretische Perspektive. [Basic elements of a theory of social practices: A perspective in social theory]. ZfS Zeitschrift für Soziologie, 32(4), 282-301. https://doi.org/10.1515/zfsoz-2003-0401.

Rose, N. (1988). Calculable minds and manageable individuals. History of the Human Sciences, 1(2), 179-200. https://doi.org/10.1177/095269518800100202.

Rule, P., \& Modipa, T. R. (2012). "We must believe in ourselves": Attitudes and experiences of adult learners with disabilities in KwaZulu-Natal. South Africa. Adult Education Quarterly, 62(2), 138-158. https://doi.org/10.1177/0741713611400303.

Rychen, D. S., \& Salganik, L. H. (2003). A holistic model of competence. In D. S. Rychen \& L. H. Salganik (Eds.), Key competencies for a successful life and a well-functioning society (pp. 41-62). Seattle: Hogrefe \& Huber.

Schnurr, S. (2005). Partizipation [Participation]. In H.-U. Otto \& H. Thiersch, H. (Eds). Handbuch Sozialarbeit Sozialpädagogik [Manual of social work and social pedagogy] (3rd edn) (pp. 13301345). Munich: Ernst Reinhardt Verlag.

Sellar, S. (2015). Data infrastructure: A review of expanding accountability systems and large-scale assessments in education. Discourse: Studies in the Cultural Politics of Education, 36(5), 765777. https://doi.org/10.1080/01596306.2014.931117.

Schreiber-Barsch, S., \& Rule, P. (forthcoming). Shifting lenses to a participatory ethos in research: Adult learners with disabilities in Germany and South Africa. In A. Köpfer, J.W. Powell \& R. 
Zahnd (Eds), Handbuch Inklusion International: Globale, nationale und lokale Perspektiven auf Inklusive Bildung[Handbook inclusion international: Global, national and local perspectives on inclusive education]. Opladen: Barbara Budrich.

Schreiber-Barsch, S., Curdt, W., \& Gundlach, H. (2020). Whose voices matter? Adults with learning difficulties and the emancipatory potential of numeracy practices. ZDM Mathematics Education, 52(3), 581-592. https://doi.org/10.1007/s11858-020-01133-1.

Smith, W. C. (2017). An introduction in the global testing culture. In W. C. Smith (Ed.), The global testing culture: Shaping education policy, perceptions, and practice (pp. 7-23). Oxford: Symposium Books.

Stalker, K. (2014). Theorizing the position of people with learning difficulties within disability studies: Progress and pitfalls. In N. Watson, A. Roulstone, \& C. Thomas (Eds.), Routledge handbook of disability studies (pp. 122-135). New York: Routledge.

Straka, G. A., \& Macke, G. (2009). Berufliche Kompetenz: Handeln können, wollen und dürfen [Professional competence: Being able, willing and allowed to act]. Berufsbildung in Wissenschaft und Praxis (BWP), 3, 14-17.

Strauss, A., \& Corbin, J. (1990). Basics of qualitative research: Grounded theory procedures and techniques. Beverly Hills, CA: SAGE.

Street, B., Baker, D., \& Tomlin, A. (2008). Navigating numeracies: Home/school numeracy practices. Dordrecht: Springer.

Strübing, J. (2014). Grounded theory: Zur sozialtheoretischen und epistemologischen Fundierung eines pragmatistischen Forschungsstils [Grounded theory: The social-theoretical and epistemological foundation of a pragmatic research style]. Wiesbaden: Springer VS.

Tan, P., Lambert, R., Padilla, A., \& Wieman, R. (2019). A disability studies in mathematics education review of intellectual disabilities: Directions for future inquiry and practice. Journal of Mathematical Behavior, 54, Art. 100672. https://doi.org/10.1016/j.jmathb.2018.09.001.

Tikly, L. (2015). What works, for whom, and in what circumstances? Towards a critical realist understanding of learning in international and comparative education. International Journal of Educational Development, 40(C), 237-249. https://doi.org/10.1016/j.ijedudev.2014.11.008.

Townsend, A. (2013). Principled challenges for a participatory discipline. Educational Action Research, 21(3), 326-342. https://doi.org/10.1080/09650792.2013.815038.

UN (United Nations) (2006). Convention on the rights of persons with disabilities. A/RES/61/106. New York: United Nations. Retrieved 2 July 2020 from https://www.un.org/disabilities/documents/conve ntion/convoptprot-e.pdf.

UN (2015). Transforming our world. The 2030 Agenda for sustainable development. [A/RES/70/1]. New York: United Nations. Retrieved 27 June 2020 from https://www.un.org/ga/search/view_doc. asp?symbol=A/RES/70/1\&Lang=E. Accessed 27 June 2020.

von Unger, H. (2014). Partizipative Forschung: Einführung in die Forschungspraxis [Participatory research: Introduction to research practice]. Wiesbaden: Springer VS.

Waldschmidt, A. (2017). Disability goes cultural: The cultural model of disability as an analytical tool. In A. Waldschmidt, H. Benessen, \& M. Ingwersen (Eds.), Culture - theory - disability: Encounters between disability studies and cultural studies (pp. 19-27). Bielefeld: Transcript.

Walmsley, J., \& Johnson, K. (2016). Vorwort [Foreword]. In T. Buchner, O. Koenig, \& S. Schuppener (Eds.), Inklusive Forschung: Gemeinsam mit Menschen mit Lernschwierigkeiten forschen [Inclusive research: Researching together with people with learning disabilities] (pp. 9-12). Bad Heilbrunn: Verlag Julius Klinkhardt.

Weisser, J. (2018). Inklusion, Fähigkeiten und Disability Studies [Inclusion, skills and disability studies]. In T. Sturm \& M. Wagner-Willi (Eds.), Handbuch schulische Inklusion [Handbook of inclusion at school] (pp. 93-106). Opladen/Toronto: Barbara Budrich.

Williams, V., Tarleton, B., Heslop, P., Porter, S., Sass, B., Blue, S., et al. (2018). Understanding disabling barriers: A fruitful partnership between disability studies and social practices? Disability \& Society, 33(2), 157-174. https://doi.org/10.1080/09687599.2017.1401527.

Witzel, A. (2000). Das problemzentrierte Interview [The problem-centred interview]. Forum Qualitative Sozialforschung/Forum: Qualitative Social Research, 1(1), Art. 22. https://doi.org/10.17169/fqs1.1.1132. Retrieved 19 January 2019 from http://www.qualitative-research.net/index.php/fqs/article/ view/1132/2520.

WHO (World Health Organization). (n.d.). Definition: Intellectual disability [dedicated webpage]. Geneva: World Health Organization. Retrieved 12 July 2020 from https://www.euro.who.int/en/ 
health-topics/noncommunicable-diseases/mental-health/news/news/2010/15/childrens-right-tofamily-life/definition-intellectual-disability.

WHO (2001). International classification of functioning, disability and health. Geneva: World Health Organization. Retrieved 7 July 2020 from https://apps.who.int/iris/bitstream/handle/10665/42407 19241545429.pdf.

WHO. (2007). Atlas: Global resources for persons with intellectual disabilities. Geneva: World Health Organization.

Wright, M. T., Roche, B., von Unger, H., Block, M., \& Gardner, B. (2010). Zur Notwendigkeit einer wissenschaftlichen Fundierung der Partizipativen Gesundheitsforschung [On the need for a scientific foundation for participatory health research]. In M. T. Wright (Ed.), Partizipative Qualitätsentwicklung in der Gesundheitsförderung und Prävention [Participatory quality development in health promotion and prevention] (pp. 221-232). Bern: Hans Huber.

Yasukawa, K., Jackson, K., Kane, P., \& Coben, D. (2018a). Mapping the terrain of social practice perspectives of numeracy. In K. Yasukawa, A. Rogers, K. Jackson, \& B. Street (Eds.), Numeracy as social practice: Global and local perspectives (pp. 3-17). London/New York: Routledge.

Yasukawa, K., Rogers, A., Jackson, K., \& Street, B. (2018b). Numeracy as social practice. Global and local perspectives. London/New York: Routledge.

Publisher's Note Springer Nature remains neutral with regard to jurisdictional claims in published maps and institutional affiliations.

Wiebke Curdt PhD, is a Research Assistant in the Department of Adult and Further Education, Unit of Lifelong Learning, at the University of Hamburg in Germany. Her research interests are inclusive education and sports (with particular emphasis on persons with learning difficulties), participatory research approaches, and numeracy and disability as part of adult basic education.

Silke Schreiber-Barsch PhD, is an Assistant Professor of Adult Education at the University of Hamburg (Germany), Faculty of Education, Unit of Lifelong Learning, and an Associated Junior Professor at the UNESCO-Institute for Lifelong Learning, Hamburg. Her main research areas are international and comparative adult education, theory and practices of lifelong learning, issues of participation and social inclusion/exclusion, with particular emphasis on adult education and disability, and global citizenship education. She is also a Research Associate at Stellenbosch University, Centre for Higher and Adult Education, in South Africa. 